\title{
Poesía y espiritualidad en Francisco de Aldana. A vueltas con la "Carta a Arias Montano» y más versos sacros
}

\author{
Sergio Fernández López \\ Universidad de Huelva \\ sergio.fernandez@dfesp.uhu.es
}

Recepción: 06/04/2018, Aceptación: 21/05/2018, Publicación: 11/12/2018

\section{Resumen}

De los numerosos estudios que ha recibido la poesía de Francisco de Aldana en las últimas décadas, su "Carta a Arias Montano» ha monopolizado la mayor parte. En muchos de ellos, la epístola, además de aparecer determinada en parte por la autoridad teológica del destinario, se presenta como culminación de un proceso del que los restantes poemas religiosos eran un mero esbozo. Estos, sin embargo, no solo tienen pleno sentido al margen de su obra maestra, sino que reflejan una espiritualidad típicamente franciscana asentada ya en la familia Aldana y afín al misticismo que exhiben algunas obras de Arias Montano. Fue seguramente esa comunidad de credos la que propició el encuentro entre poeta y biblista.

\section{Palabras clave}

Francisco de Aldana; Carta a Arias Montano; poesía religiosa; espiritualidad franciscana

\begin{abstract}
Poetry and spirituality in Francisco de Aldana. A new reading of 'Letter to Arias Montano' and other devotional verse

Among the numerous studies in recent decades of the poetry of Francisco de Aldana, "Carta a Arias Montano" has received the most attention. In many studies, this epistle - in addition to being determined in part by the theological authority of its recipient-is taken to be the culmination of a process in which the other religious poems are a mere sketch. These other poems, however, both have their own significance, independent of the epistle, and also reflect a typically Franciscan spirituality existing in the Aldana family and akin to the mysticism evident in several works by Arias Montano. It was surely this coincidence of beliefs that brought about the meeting between the poet and the biblical scholar.
\end{abstract}

\section{Keywords}

Francisco de Aldana; Epistle to Arias Montano; religious poetry; Franciscan spirituality 
$Y$ qué debiera ser, bien contemplando, el alma sino un eco resonante.

Extrañaban a Rodríguez Moñino las dos direcciones principales y, en su opinión, divergentes, de la poesía de Francisco de Aldana. El bibliófilo extremeño se resistía a aceptar en 1943 que, sin apenas espacio cronológico para cambiar, Aldana escribiese casi al unísono ora las «octavas a Felipe II», ora su famosa "Carta a Arias Montano», política y activa la una, ascética y contemplativa la otra: «Cómo relacionar, pues, dos orientaciones tan opuestas como lucha y quietud, tierra y cielo, acción y contemplación?», se preguntaba luego. ${ }^{1}$ A contestar esta y otras cuestiones similares han venido ya un sinfín de artículos, ediciones y monografías sucesivas, pues si durante poco más de tres siglos apenas Menéndez Pelayo había osado rescatar del olvido y del silencio más atronador a nuestro poeta, y algún que otro antólogo se había atrevido a incluir una fugaz muestra de su obra, las últimas décadas han visto convertir al otrora poeta casi secundario en un verdadero referente de la poesía de su tiempo. ${ }^{2}$

Con todo, es cierto que, a zaga seguramente del propio Rodríguez Moñino, la mayor parte de ellos han centrado sus esfuerzos en la línea religiosa, pues, como quería su editor, «lo fundamental de Aldana no es la vida exterior, sino la íntima». ${ }^{3}$ Como fuere, al margen de su faceta político-militar, cada vez más y mejor trabajada, los estudios que abordan las restantes líneas de su poesía son ya legión. Cada uno, además, ha sabido entresacar con pericia una particularidad nueva en sus versos, arrimando a menudo el ascua a su sardina y encareciendo sobremanera quizá aquellas influencias que tienen más parte en su alma, a decir de Baltasar del Alcázar. De ahí que algunos hayan visto en el joven Aldana a un neoplatónico «a lo Ficino», ${ }^{4}$ junto a otros que, aun asumiendo su neoplatonismo, han preferido calificarlo de "cristiano y típicamente español», diferente al de la Academia florentina; 5 del mismo modo que no han faltado quienes destaquen su "lírica metafísica», ${ }^{6}$ quienes han acentuado sin tapujos el misticismo de sus versos, ${ }^{7}$ los que han visto en su poesía una evolución al animismo religioso y

1. Rodríguez Moñino (1946: 22).

2. Entre sus editores, por ejemplo, pueden citarse, junto al mencionado Rodríguez Moñino (1943; 1946), las publicaciones de Rivers (1957), Ruiz (1984), Lara Garrido (1985) o Navarro (1994).

3. Rodríguez Mońino (1946: 22). Sin ánimo por supuesto de ser exhaustivos, valga por ahora la mención de algunos estudios de su poesía sacra, como los de Vossler (1944), Lefebvre (1953), Ruiz Silva (1981), Volpi (1995), Lara Garrido (2001) o Gómez Canseco (2007).

4. Rivers (1955: 35).

5. Green (1969: 155).

6. Cernuda (1948).

7. Menéndez Pelayo (1941), Ruiz Silva (1981). 
organicismo desde un animismo laico, ${ }^{8}$ quienes han considerado a nuestro poeta un asceta que recrea el goce contemplativo en sus versos, frente a quienes los estiman, en cambio, muestra de su «aspiración a la unión mística con Dios», 9 e incluso quienes admiten, en fin, que Aldana desemboca en un claro misticismo, pero desde un humanismo erasmista. ${ }^{10}$ En este último sentido, debo advertir que, aun estando de acuerdo en líneas generales con cada apreciación, no creo, sin embargo, que la poética de Aldana deba mucho al erasmismo, si bien es verdad que la afinidad espiritual entre muchas de las corrientes religiosas que se desarrollaron en España a principios del siglo xvı era considerable. Pero tiempo habrá de tratar de esta cuestión.

Todos o casi todos, no obstante, parecen aceptar y así lo anotan en sus trabajos la evolución de su "proceso poético», de un Aldana platonizante y sensual a un Aldana religioso. Claro que no entendido por muchos como un proceso evolutivo lineal e histórico, aunque puedan diferenciarse al cabo en su obra poéticas diferenciadas, hasta el punto de reconocerse al final de sus días la desaparición total de aquel primer poeta amoroso de época florentina, en el que el amor a Dios habría ido relegando, hasta su desaparición final, al amor mundano. Por eso, los últimos estudios han preferido hablar con acierto quizá de coexistencia de lógicas poéticas, por momentos contradictoria, que presenta a tres Aldanas distintos a un tiempo en franca convivencia ${ }^{11}$, frente a los que habían optado por asimilar el posible proceso evolutivo de su poesía a sus propios avatares vitales. Su juventud en la corte medicea llevaría así para estos últimos a la poesía laica y neoplatónica. Su posterior trasiego como soldado lo llevaría luego a la práctica de una poesía político-militar. Por último, desengañado de la vida castrense y de la milicia, después de superar una profunda crisis espiritual, llegaría su postrera poesía religiosa, del retiro y la contemplación, una vez rechazados también sus inicios poéticos por amorales. ${ }^{12}$

A nadie se le escapa, por lo demás, que de todos sus versos han sido los que conforman la famosa «Carta a Arias Montano» los que han recibido mayor atención, a enorme distancia del resto. Apenas hay rasgo de ella que no haya sido abordado, tanto desde el profundo contenido humanístico y religioso, como desde el punto de vista genérico. Así, se ha destacado su sentido doctrinal y moral, característico de la epístola clásica. Aún más, se ha elevado a una «epístola

\footnotetext{
8. Rodríguez (1990); García (2010: 101).

9. Green (1969: 187).
}

10. Ruiz Silva (1981: 231); García (2010).

11. Que no niega, en cualquier caso, que haya un proceso vital y poético que lleva a Aldana a rechazar su poesía amorosa primera.

12. Así lo entienden, entre otros, Rodríguez Moñino (1943), Lefebvre (1953) o Rivers (1955). Por el contrario, Rosa Navarro, por ejemplo, advierte que, dada la imposibilidad de establecer una cronología fiable de su poesía, "no es posible hablar ni de etapas ni de evolución en su obra» (1994: X-XI). 
horaciana a lo divino» ${ }^{13}$ e incluso se ha visto en ella una auténtica sátira epistolar. ${ }^{14}$ Por supuesto, también aquí se ha tratado de situar en su contexto histórico, analizándose entonces como poema fronterizo, que vislumbra el paso del tono vivencial o confesional a la abstracción más despersonalizada y doctrinal de Trento, del neoplatonismo amoroso al humanismo cristiano y de lo clásico renacentista, en definitiva, a lo ya netamente barroco. ${ }^{15}$

De un modo u otro, sea o no acertado este análisis historicista y lineal de su poesía, no cabe duda de que la epístola de Aldana demuestra, una vez más, el interno proceso evolutivo de sus versos, que lo llevaron al final de sus días hacia una poesía de profundo contenido religioso, de la que esta "Carta a Arias Montano» es sin duda cumbre. No en vano, es a ella a la que debe seguramente su apodo de «el Divino» capitán y por la que muchos de sus estudiosos lo han llegado a considerar un auténtico místico.

A este respecto, comenta Lefebvre, sin embargo, que la carta está lejos de tratarse de un poema doctrinal y aún menos de un tratado de mística. En su opinión, Aldana escribe poesía y no teología, entre otras cosas porque ni «es un místico en el sentido técnico de la palabra», ni "tampoco es un especialista en materias teológicas y ascéticas». ${ }^{16}$ Por supuesto, no le faltan razones a Lefebvre para afirmar que el divino Capitán no era desde luego ningún teólogo, ni tampoco un gran experto en materia mística. No serán estas líneas las que lo pongan en duda. Pero sí creo importante destacar que el dominio que cualquier poeta del siglo Xvi tenía sobre la materia sagrada de su tiempo era seguramente muy superior al que quizá le suponen algunos de sus estudios y que el conocimiento que, más concretamente, poseía Aldana sobre el asunto resulta tan abrumador como incuestionable y tiempo habrá para comprobarlo. En este sentido, estimo mucho más acertada la opinión de Ruiz Silva, para quien "Aldana poseyó una auténtica cultura teológica y ese profundo conocimiento teológico lo utilizó como campo poético con especial acierto». ${ }^{17}$

Volviendo a la "Carta a Arias Montano», fue seguramente su primer exégeta riguroso quien la leyó como génesis o punto de partida de su restante obra, como si esta tuviese sin más un carácter suplementario, secundario o accesorio dependiente de la epístola, que lo presidía todo. Para Lefebvre, pues, el resto de la producción poética de Francisco de Aldana debía de leerse en función de la carta, pues sin ella lo demás carecía de auténtico valor. ${ }^{18} \mathrm{Y}$ no fue el único de esa opinión. También Prieto, entre otros, llega a bosquejar un panorama similar, en el que toda la poesía del Capitán confluye en la carta, de tal modo que, si bien

\author{
13. Rivers (1955: 175). \\ 14. Pozuelo Calero (2000: 92). \\ 15. Véase sobre esta cuestión el completísimo estudio de García (2010). \\ 16. Lefebvre (1953: 95). \\ 17. Ruiz Silva (1981: 129). \\ 18. Lefebvre (1953).
}


el resto no cobra de manera tan evidente verdadero significado a su luz, sí que la sitúa en la cumbre de su afán poético. ${ }^{19}$

Podría criticarse que, atendiendo a este modo de elucidación, especialmente si nos ceñimos al que respalda Alfredo Lefebvre, la perspectiva de proceso creativo y radical historicidad de su poesía parece difuminarse, como advertía Miguel Ángel García. ${ }^{20}$ Sin embargo, creo que, en cierto modo, su visión resulta totalmente acertada, quizá no en el sentido de que sus versos cobren solo sentido a la luz de su obra maestra, sino en el de que sus poemas anteriores anuncian sin duda el Aldana final, mostrando así un poeta de una pieza y una poesía cabalmente unitaria desde mi punto de vista, que evoluciona del mismo modo que el Góngora de las Soledades ya se encontraba aquí y allí en sus anteriores sonetos.

Los poemas de corte sacro que se han conservado de Aldana no son intentos fallidos o esbozos de su loada "Carta a Arias Montano». Son más bien reflejo de unos intereses que van a perdurar en el tiempo y que ya se encontraban en el joven poeta. No creo que sus poemas religiosos anuncien nada. Simplemente hay que situarlos en su momento y entender que el Aldana último ya se encontraba en germen en el primero y que este Aldana podía entablar diálogo con el postrero sin la menor estridencia. ${ }^{21}$ La presentación de un poeta unitario resulta además, en mi opinión, de vital importancia para valorar en su justa medida no solo su poesía religiosa menos conseguida, sino la misma "Carta a Arias Montano", sobre todo si la ponemos en relación con su afamado destinatario y su posible influencia en su composición.

No son pocos los estudiosos de la epístola que han señalado su deuda con Benito Arias y con el «familismo» flamenco del que, supuestamente, participaba el humanista extremeño. Uno de ellos, seguramente el primero y el que con mayor énfasis llegó a plantearlo, fue Ángel Alcalá. En su opinión, queda claro que Francisco de Aldana y Arias Montano se conocieron en Flandes, a donde ambos llegaron por distintos motivos, en 1567 el uno y en 1568 el otro. Y no solo eso. Para Alcalá, la carta debía de leerse a la vista del nuevo familismo montaniano, pues le parecía muy posible que Aldana se hubiese iniciado en Amberes en aquella secta. A ello atribuye este investigador, de hecho, su «incipiente pacifismo», "su apología del alma y de los caminos de evasión contemplativa», y «su insistencia en la luz y su énfasis en la quietud, en el sosiego». ${ }^{22}$ Es más, años más tarde, llega a afirmar que Aldana sufre una autentica conversión, debida no solo a su lectura del Dictatum de Arias Montano, sino sobre todo a su contacto con la Familia Charitatis a la que pertenecía el humanista extremeño:

19. Prieto (1984). Más de acuerdo con él que con Lefrebvre, Lara Garrido (1985: 16-17).

20. García (2010: 692).

21. Lógicamente, el problema de la cronología de sus poemas, de la que apenas se conocen ciertas fechas, impide confirmarlo con mayor certeza. Con todo, la fecha aproximada de algunos sí permite comprobar en mayor o menor medida que esas inquietudes espirituales acompañaron al poeta hasta el final de sus días.

22. Alcalá (1973: 249-250). 
He defendido que el largo poema de 450 versos en tercetos que desde Madrid, a siete de septiembre de 1577 , le dedica Aldana a Montano «sobre la contemplación de Dios y los requisitos della», trasluce no solo la posible reacción de un lector del Dictatum, sino gran intimidad y una serie de emotivas confesiones espirituales no reducibles a tópicos genéricos, no explicables por meras referencias al neoplatonismo o al erasmismo o a una crisis imprecisa, sino por cierta «conversión» religiosa, más que simplemente espiritual, determinada por el mismo Montano. ${ }^{23}$

De la misma opinión ha sido Ruiz Silva. Montano habría entrado en contacto con el familismo flamenco a través del architipógrafo regio, el gran Cristóbal Plantino, y a través de aquel el mismo Francisco de Aldana. Aunque nunca llega a afirmar con rotundidad que el poeta tuviese unas creencias religiosas concretas ni que los versos de su carta formularan una doctrina precisa, sí consideraba indudable que existían en ella «elementos erasmistas, como el desdén por las formas de religiosidad exterior, y otra serie de rasgos que pudieran sugerir una influencia de los «familistas» flamencos a través de Arias Montano». ${ }^{24}$ En la misma «Familia Charitatis» lo inserta Raúl Ruiz, ${ }^{25}$ quien también señala a Montano como culpable de aquella nueva religiosidad, seguidora de la devotio moderna y contraria a toda liturgia, del poeta.

Es, por último, Lara Garrido quien vuelve a conectar la carta del divino Capitán con el humanista y su Dictatum Christianum, que Aldana debió de leer, bien en Flandes, bien en Madrid a partir de julio de $1576,{ }^{26}$ fecha en la que Montano llega de nuevo a la corte después de años de ausencia. ${ }^{27}$ Sin embargo, para Lara Garrido una cosa era la influencia en Aldana del tratado espiritual del humanista y otra muy distinta su inclusión en la citada «secta del amor», pues las características de la carta, que la crítica había reseñado como propias del familismo, las presumía al cabo propias de cualquier otra "corriente de mística afectivista». ${ }^{28}$

Lo que sí parece quedar fuera de duda, perteneciese o no a la Familia Charitatis, es que Aldana no solo conoció y leyó la Lección cristiana de Arias Montano, sino también otras obras del humanista, cuyo pensamiento y aficiones salieron a relucir en la epístola. A nadie se le escapa que tras estos versos del Capitán, «serán temor de Dios y penitencia / los brazos, coronada de diadema / la caridad, valor de toda esencia» (vv. 349-351), ${ }^{29}$ se encontraba la descripción de la piedad que vertebra el Dictatum: «La suma de esta verdadera piedad i servicio de Dios, de que avemos començado a tratar, para que se sepa y egercite, se divide en tres partes, que son

23. Alcalá (1998: 99) no solo insiste aquí en la conversión familista de Aldana, sino que se asombra incluso de que otros estudiosos como Lara Garrido no sean de esa misma opinión.

24. Ruiz Silva (1981: 231).

25. Raúl Ruiz (1985: 25).

26. Lara Garrido (1985: 437).

27. Morocho (1999: 266-269).

28. Lara Garrido (1985: 437).

29. La poesía de Aldana se cita por la edición de Lara Garrido (1985). 
temor, penitencia y caridad». ${ }^{30}$ Del mismo modo que en estos otros, con los que se cierra prácticamente la epístola, «En fin, Montano, el que temiendo espera / y velando ama, solo este prevale / en la estrecha, de Dios, cierta carrera» (vv. 433-435), no ha faltado quien reconozca los peligros del sueńo o la pereza y la necesidad de velar para alcanzar el gozoso premio de allegarse a Dios, así como la conexión entre temor y amor divino, que Montano exhibe de nuevo en su Dictatum. ${ }^{31}$

Lo mismo cabría decir de ese anhelado retiramiento que comunica con Montano y que este había deseado no solo para sí durante toda su vida, como confesó por carta a Gabriel de Zayas, sino también para sus propios amigos, como paso necesario a la purificación del alma, el conocimiento de sí mismo y la contemplación posterior. Así se lo hizo saber, por ejemplo, a otro poeta amigo suyo, en la dedicatoria de uno de los salmos elucidados por el humanista:

No solo alabo ese propósito, sino que también te felicito, porque aunque por fortaleza física, edad, cualidades, recursos, distinción y posición se considera que puedes ceder muy pocos de los que desean y frecuentan grandes castillos y regias ciudades y cortes, has decidido llevar una vida privada libre de las argucias de la ambición y exenta de malsanas preocupaciones, ajena a la conducta que suele concitar envidia y al margen de las intrigas, en una población más pequeña, pero muy agradable. Pues así ciertamente has adquirido una condición mejor y mucho más apetecible... ${ }^{32}$

Seguramente, tampoco extrańe a nadie que Aldana abogara por el estudio y el conocimiento que solían seguirse a menudo de aquel retiro. A este respecto, no creo que sea casualidad el hecho de que la capilla florentina de la familia Aldana estuviese dedicada a san Jerónimo. Quizá, Antonio de Aldana, padre de nuestro poeta, tuviese presente, cuando esta se erigió, el fresco de san Jerónimo de Ghirlandio que estaba próximo al altar, junto al de san Agustín de Boticelli. Pero de lo de no cabe duda ninguna es de que ambos santos recordaban que la vía de acceso a la salvación solo era posible a través del estudio. ${ }^{33} \mathrm{~A}$ esta misma idea quería aludir posiblemente el propio Montano cuando eligió como emblema personal la imagen de Arquímedes saliendo del baño y gritando "eureka», pues la anécdota, más allá de remitir a la cultura clásica que asistía a todo humanista, simbolizaba como pocas el triunfo del estudio y el conocimiento.

Pero la cuestión no quedaba ahí. Como también señaló Gómez Canseco, aquella estampa, que Montano incluyó por cierto en la portada de la Biblia Regia, subrayaba aún más el «carácter de revelación y de iluminación repentina que se

30. Pedro de Valencia, La «Lección cristiana» de Arias Montano, p. 185.

31. Véase, por ejemplo, Gómez Canseco (2007: 156) y Lara Garrido (2001: 380).

32. Benito Arias Montano, Comentario a los XXXI primeros salmos, p. 81. Llevo algunos ańos ocupado en la edición de la obra de este poeta y amigo de Montano, llamado Pedro Mudarra, que espero publicar lo antes posible.

33. González Talavera (2011: 271). 
escondía tras ese conocimiento». ${ }^{34}$ La conexión, desde luego, no debía de andar muy errada cuando se sabe que algunos discípulos de Arias Montano, y así lo afirmó el mismo don Benito, creían que el dominio de la sagrada Escritura que poseía su maestro excedía al que podía alcanzarse por vía humana. Pues bien, no lejos de esa concepción del conocimiento superior, casi divino, del humanista extremeño pueden situarse una vez más los versos iniciales del poema mayor de Aldana, en los que confiesa de Montano ser «nombrado así por voluntad divina / para mostrar que en ti comienza Apolo / la luz de su celeste disciplina» (vv. 4-6).

En definitiva, los versos de la epístola evidencian que Aldana admiraba al eximio biblista y que conocía perfectamente tanto su obra poética y doctrinal, como sus más queridas aficiones ${ }^{35}$. Pero también me resulta evidente que Montano no la determina en ningún caso — si se quiere, la enriquece—, del mismo modo que tampoco creo que la carta muestre una suerte de conversión religiosa provocada por el humanista, entre otras cosas porque sus versos reflejan la misma espiritualidad de otros poemas que la crítica ha situado algunos años antes. Es más, si se atiende a los textos poéticos en los que Montano aborda asuntos como la contemplación, plantea principios ascéticos o conjuga elementos místicos, podríamos afirmar sin temor a equivocarnos que su formulación coincide en grandísima parte con la que expusieron san Buenaventura, Francisco de Osuna y Bernardino de Laredo, paradigmas de la mística franciscana. Y es aquí, sin lugar a dudas, donde se encuentra la verdadera conexión con el autor de la carta. No hay que olvidar que la relación de la religiosidad franciscana con la familia Aldana alcanza, cuando menos, a su mismo padre, como habrá ocasión de comprobar. De ahí que no crea que el poeta fuese captado por Arias Montano para ninguna secta. Antes bien, el encuentro y acercamiento entre ambos debió de facilitarlo el hecho de que ambos profesaran una misma espiritualidad, que ya se encontraba en Aldana desde muy joven. La amistad, pues, vendría por añadidura. ${ }^{36}$

Fue Rodríguez Moñino el primero que relacionó a Francisco de Aldana con la villa de Alcántara, hasta el punto de que la consideró lugar de nacimiento del poeta. La apreciación, sin embargo, fue matizada con los años, pues, según pare-

34. Gómez Canseco (2007: 115).

35. De su poesía no se ha hablado aquí por cuestiones lógicas de espacio. Para ello, remito al estudio de Gómez Canseco (2007), donde se establecen con gran acierto conexiones entre la poesía contemplativa y por momentos mística de Montano y no pocos versos de Aldana. En cuanto al conocimiento que nuestro poeta tenía de las aficiones montanianas, baste citar la alusión a las conchas y caracolas que recoge la «Carta a Arias Montano» ya señalada por la crítica. 36. En este sentido, considero que la relación con Aldana dista de la que mantuvo con otras personas del entorno montaniano, como podrían ser Pedro de Valencia o fray José de Sigüenza, en los que sí se dio claramente una suerte de magisterio y me atrevería a decir de influjo casi hipnotizador, propiciado quizá por la mayor diferencia de edad. Esto no quiere decir, por supuesto, que Aldana no reconociese la autoridad teológica de Montano, pues esta queda patente en la carta, sino que fue seguramente aquella coincidencia de pareceres y creencias la que los acercó. 
ce, para entonces la familia ya se encontraba en Nápoles. ${ }^{37}$ Con todo, el origen alcantarino de su linaje queda fuera de duda. La relación no es baladí. Y es que fue precisamente en esta zona extremeña donde la rama franciscana de la descalcez, iniciada por Juan de la Puebla, ${ }^{38}$ resurgió con fuerza tras su descaecimiento a finales del siglo $\mathrm{xV}$, entregada a una vida intensa de oración y retirada a lugares solitarios y apartados en busca de la perfección. ${ }^{39}$ Es más, Melquíades Andrés llega a afirmar que fue precisamente en ese tipo de eremitorios extremeños, así como en los recolectorios y casas de oración de otras provincias, donde nació el esquema de la futura mística franciscana del siglo XvI. ${ }^{40}$

Para este mismo estudioso, la vida en aquellos conventos extremeños destacaba por dos aspectos que conectan directamente con la poesía religiosa de nuestro autor. Por un lado, la primacía concedida al amor, como manifestación de la voluntad. De ahí que la clave de aquella vida espiritual franciscana estuviese más «en la sapiencia que en la ciencia, en la gracia que en la doctrina, en el deseo que en el entendimiento». ${ }^{41}$ Se trata de la misma idea que propuso el divino Capitán en el poema «De cuál de los dos más goce en el cielo: el entendimiento o la voluntad», cuando afirma en el último terceto: «siendo fuego el amor, mostrarnos quiso / que tiene cerca dél más alto grado / quien con alas de amor más alza el vuelo» (356). ${ }^{42}$ La coincidencia ideológica con el Tercer abecedario espiritual de Osuna no es desde luego casual y mucho menos la alusión a las «alas de amor» que había mencionado el fraile sevillano. ${ }^{43}$ Es cierto que Osuna se sirve a veces de las alas para simbolizar la pobreza y la humildad necesarias para la alcanzar la contemplación y que incluso en la tercera parte de su Abecedario afirma que las alas representan también la voluntad y el entendimiento. Pero son siempre las «alas de amor o deseo» y no las del entendimiento las que se ejercitan en el más alto vuelo contemplativo, para el que nada aprovechan los sentidos, como afirma en este pasaje del Primer abecedario: «Nuestra Águila caudal —Cristo-, viendo que sus hijos, los apóstoles, no se ejercitaban en el vuelo alto de la contemplación divina [...], quitoles el manjar, que era su mesma presencia [...].

37. Rivers (1955: 24); Lara Garrido (1985: 21).

38. Lejarza (1962). Aunque confinados por estas fechas prácticamente a Extremadura y zonas colindantes, como la sierra norte de Sevilla y Córdoba, lograron extenderse también a Portugal, donde fundaron el convento de la Piedad.

39. Aunque parezcan notas poco significativas, desde la austeridad hasta la oración mental, pasando por el gusto por el retiro y la sencillez de los edificios, encerraban notables novedades en relación con la vida que se llevaba por lo común en los conventos de frailes, como señalan Abad y Sánchez (1999: 460).

40. Andrés Martín (1988: 472). Para un tratamiento amplio del asunto, Andrés Martin (1994).

41. Andrés Martín (1988: 466).

42. La página remite a la edición de Lara Garrido (1985).

43. Como advierte Andrés Martín (1988: 477), en la sistematización codificada de la mística del recogimiento asentada en Extremadura y otros lugares, Francisco de Osuna distinguió tres clases de oración: vocal, de pensamiento o de toda alma y, por último, espiritual o de alta contemplación, «con la que lo más alto de nuestra alma se alza más pura y afectuosamente a Dios con las alas del deseo y piadosa afección, esforzada por el amor». Tercer Abecedario espiritual, p. 366. El subrayado es mío. 
Y así aprendieron a salir del nido, que es el cuerpo donde el ánima se alberga. Y digo que salieron del nido porque volaron con las alas de fe y amor, dejando los cinco sentidos del nido, que para contemplar la divinidad ninguna cosa aprovechan». ${ }^{44}$

Por otro, la importancia del silencio de la soledad eremítica como senda para encontrarse con Dios, alma sola y Dios solo, de acuerdo de nuevo con la máxima de Francisco de Osuna: «Busca a Dios en tu corazón y no salgas fuera de ti, porque más cerca está de ti y más dentro que tú mismo». ${ }^{45}$ No otra cosa leemos en la "Carta a Arias Montano", cuando Aldana desea apartarse de la común carrera que sigue el vulgo y «entrarme en el secreto de mi pecho / y platicar en él mi interior hombre» (vv. 49-50). Aquella vida, en todo caso, no buscaba el aislamiento absoluto, sino la búsqueda de perfección, la integración de alma y cuerpo, que recogen numerosos versos de Aldana en los que aboga por el retiro. Esta tendencia eremítica no solo fue compartida por los recoletos franciscanos como Osuna, sino también, por supuesto, por la rama reformada de la descalcez, cuyos integrantes pretendieron desde sus inicios volver a la austeridad primitiva de la orden, lo que implicaba otorgarle un lugar primordial a esa búsqueda del silencio y la oración interior. ${ }^{46}$

Por si fuese poco, volviendo a la relación de los Aldana con los descalzos y, más concretamente en este caso, los recoletos extremeños de la orden de san Francisco, la familia estaba emparentada con la del famoso franciscano san Pedro de Alcántara a través de María de Villela, ${ }^{47}$ madre del santo, cuyo hermano se había desposado con Constanza Aldana, además de que no fueron los únicos miembros de ambas cunas que mantuvieron relación. ${ }^{48}$ Los seguidores de san Pedro, por cierto, llamados por eso mismo «alcantarinos», fueron muy sólidos en España, paralelamente a su aparición como hermanos menores reformados en Italia. Por lo demás, fue este santo franciscano quien, modificando las costumbres de la descalcez, impuso la ampliación de dos a tres horas de oración, ${ }^{49} \tan$ bien acogida por casas de recolección como la del mismo Francisco de Osuna. ${ }^{50}$

44. Francisco de Osuna, Primer Abecedario espiritual, p. 93.

45. Francisco de Osuna, Tercer Abecedario espiritual, p. 133.

46. Sobre la espiritualidad de la descalcez, véase Uribe (1962).

47. Sobre san Pedro de Alcántara y el recogimiento, véase el trabajo de Amez (1998). También, para la espiritualidad de la descalcez alcantarina, Herranz (1998).

48. Para no entretener más el asunto, véase el estudio de Bernáldez (2007), donde se alude a Gonzalo de Aldana, compañero de san Pedro en la villa de Alcántara, o a Bernardo Villela de Aldana, entre otros. En la obra Antigüedades y santos de Alcántara, p. 130, entre los caballeros y frailes de la orden, se alude también a fray Bernardo Villela de Aldana, prior de la iglesia del Real Convento situado junto a la villa de Alcántara, capellán mayor de las galeras de España y obispo de Guadix.

49. Al parecer, los conventos recoletos dedicaron cada vez más horas a la oración, según afirmaba el cronista Pedro de Salazar, hasta el punto de dedicarle la mayor parte del tiempo (Pablo Maroto, 2003: 31).

50. Para la vida de recogidos franciscanos como Osuna, sus casas y el ideario que las regía, véase el estudio de Meseguer (1961). 
La relación de la familia del poeta con la orden franciscana no quedaba aquí. Los frailes menores observantes italianos estaban asentados en el convento de san Salvatore al Monte, precisamente en las proximidades de la fortaleza de san Miniato. No hará falta recordar que Antonio de Aldana y su hijo Francisco fueron respectivamente castellano y lugarteniente de aquella fortificación. Pero es que, además, su asiento en Florencia se debió al padre español Francisco Pardo, quien mantuvo estrecha relación con Leonor de Toledo. ${ }^{51} \mathrm{Su}$ esposo, el duque Cosme I de Médici, es quien, de hecho, deja dinero a la orden para la construcción de un convento hasta su definitivo traslado a la iglesia de Ognissanti. El traslado, que se produce en 1561, se debió a la vinculación personal que Leonor de Toledo mantenía con la orden y que asimiló muy posiblemente de Antonio de Aldana, su ayo e instructor. La vinculación entre los franciscanos de Ognissanti y los españoles - acaso habría que decir con el español Antonio de Aldana- quedaría de este modo más que justificada. ${ }^{52}$ En cualquier caso, se trata solo de una posibilidad, pues la secular relación de numerosas casas nobiliarias con órdenes religiosas a través de patronatos, fundaciones y otros asuntos es conocida. ${ }^{53}$

Pero la relación iba aún más lejos. Con la llegada de los franciscanos, se produce una reforma integral de la Iglesia, de la que el duque Cosme I había expulsado a sus antiguos moradores, los umiliati. En ella actuó activamente Antonio de Aldana con la comisión de una capilla-altar en la que aún se conserva el escudo de armas de su linaje. Al fin y al cabo, el patronato y propiedad de capillas representaba una manifestación de la pietas religiosa y de la devoción familiar. ${ }^{54}$ La elección de aquella iglesia donde moraban los frailes de san Francisco para erigir el oratorio de la familia, pues, no fue casual, si se tiene en cuenta que los Aldana procedían de Alcántara, importante cuna, como sabemos, de los religiosos franciscanos asentados en ella.

Por último, no deja de resultar curioso que estos frailes menores llevaran a Ognissanti por entonces el hábito que llevaba supuestamente san Francisco cuando recibió los estigmas en el monte de La Verna, donde se conservó como reliquia del santo hasta hace pocos años. Habría que preguntarse si el poema que Aldana dedica a san Francisco, titulado "Al monte de Alverna» no lo provocó la llegada de aquella reliquia a la iglesia o incluso, por qué no, el precioso fresco de la «Sacra conversazione» que preside la capilla-altar de su familia. En el cuadro, pintado en torno a 1565 , fecha en la que el poeta aún se encontraba en Florencia, también aparece un san Francisco arrodillado, vestido con el hábito de la orden y con leve expresión de éxtasis, que podría aludir indirectamente

51. No en vano, en su testamento, Leonor de Toledo deja una donación de 1000 ducados anuales a los conventos de la orden franciscana. Véase González Talavera (2011: 270).

52. Así lo manifiesta González Talavera (2011: 271)

53. Carrasco (2000).

54. González Talavera (2011: 274). 
a la estigmatización, ${ }^{55}$ mientras es bendecido por un niño Jesús que la Virgen sostiene en su regazo.

Fuese o no así, los versos con los que Francisco de Aldana finaliza aquel poema, «lo que en Él causó mi culpa y falta, / en vos, alma especial, nos muestra Cristo / ser privilegio y don, ser gracia pura», vuelven a recordarnos la idea de que la unión con Dios la produce el amor y no el conocimiento. Y es precisamente esta idea la que se ha querido destacar con esta breve digresión donde se ha relacionado a los Aldana con la orden de san Francisco. Quiere decirse con ello, por un lado, que el poeta conocía el ideario franciscano desde muy joven y que no creo que sea posible observar gran diferencia entre su "Carta a Arias Montano" y otros poemas religiosos, más o menos cercanos cronológicamente, si no es en el mayor o menor acierto de las composiciones. De ahí que sus editores no hayan dejado de señalar como fuentes posibles de sus versos las obras de franciscanos como san Buenaventura, Francisco de Osuna o Bernardino de Laredo.

Y por otro lado, que no creo tampoco, como dije en su momento, que pueda observarse un cambio significativo ni «conversión» posible entre la espiritualidad que refleja su afamada epístola y el resto de su poesía contemplativa o devota. Por eso mismo, no es difícil de encontrar numerosas similitudes entre su poema mayor y los demás poemas sacros, que evidencian el carácter unitario de su poesía religiosa, sin que esto niegue, por supuesto, el proceso evolutivo que sufre cualquier poeta que se precie.

Así, la antigua aspiración humanística de vivir retirado del mundanal ruido que se aprecia en la carta, «Y porque vano error más no me asombre, en algún solitario nido / pienso entrar mi ser, mi vida y nombre» (vv. 52-54), no es distinta de la que recogen sus «Octavas sobre el bien de la vida retirada», escritas, según algunos investigadores, en 1565, cuando el poeta permanecía aún en Florencia: «aquí me estoy, do mi liceo / me forma un capacísimo aposento / que, aunque pequeño, en él vive el deseo / rico sin más buscar que a su contento» (vv. 82-85), y «Fundo mi habitación en valle amena / sobre alta piedra en un cimiento firme, / huyo la cumbre y la movible arena» (vv. 57-59). A decir verdad, no entiendo la supuesta contradicción que habría entre estos versos y los poemas dedicados a la milicia, como tampoco veo que aquella vida retirada, que apenas pudo llevar a la práctica, solo cobre sentido en su madurez, cuando compuso su epístola a Montano. Como ya he señalado, ese ideal de vida fue siempre una aspiración, que expresa además en bastantes textos, y muestra más que nada la inquietud espiritual que acompañó a Aldana desde sus años mozos.

Por lo demás, la belleza común a los paisajes de todo retiramiento aparece a menudo como destello de la beldad divina a la que se aspira. La hermosura y perfección de la naturaleza producen, pues, en el poeta no solo la admiración, sino la conmoción de su alma, del mismo modo que la música de Salinas pro-

55. Según la opinión de Spalding (1982: 262). 
vocaba la elevación para fray Luis. Es posible que, como apunta Miguel García, en la "Carta a Arias Montano» se destaque el amor a Dios y que de ahí se aprecie la belleza de su obra, y no al contrario. ${ }^{56}$ Pero la relación, en una dirección y otra, queda recogida en la carta, al igual que en poemas anteriores, como en las citadas «Octavas sobre el bien de la vida retirada»: «Doy gracias al Señor del alto coro / por tan diversa y temporal belleza: / todo me es escalón, todo escalera, / para el Señor de la dorada esfera» (vv. 125-128). Precisamente en este poema, de acuerdo con la mayor parte de ramas reformadas franciscanas, Aldana no propone un retiro absoluto, sino en la adecuada compañía que ayuda a mejorar y perfeccionarse. No hay que olvidar que si a muchas casas franciscanas las denominaron mayormente eremitorios no fue porque se construyesen siempre en antiguas ermitas o porque la vida de sus habitantes se asemejase del todo a la de los ermitańos, sino para designarlas con un nombre que representase la humildad a la que aspiraban, frente a los grandes edificios conventuales, como bien explicaron los padres Lejarza y Uribe. ${ }^{57}$ De hecho, podían gozar de un trato cordial con sus hermanos, relacionarse a través de la predicación e incluso, una vez sosegados los ánimos, cultivar estudios de artes y teología. ${ }^{58}$ Se trata, en fin, del ideario que rezuman los versos de Aldana, pues si en la carta el poeta desea disfrutar de su recogimiento junto a Arias Montano, en las octavas lo hace junto a «dos amigos y un conforme hermano» (v. 26).

En ese proceso, el poeta intenta alejarse de este mundo, despojarse del lazo que lo ata a lo terreno y que impide el vuelo del alma, que se encuentra «dentro la cárcel del corpóreo afeto» (v. 154). Por eso, tras reconocer la vanidad del mundo y de los afanes terrenales, es lógico que Aldana busque en la carta alcanzar la patria verdadera del alma, volver al origen, que es "causa del ser mío" (v. 141): "pienso torcer de la común carrera / que sigue el vulgo y caminar derecho / jornada de mi patria verdadera». De nuevo se trata del mismo peregrinaje espiritual que exhiben poemas como el soneto "Al cielo»: « $\mathrm{Oh}$ patria amada, a ti sospira y llora / ésta en su cárcel alma peregrina, / llevada errando de uno en otro instante» (vv. 9-11), o como este otro, titulado «Reconocimiento de la vanidad del mundo", donde se llega igualmente a la conclusión de que no hay mejor modo de vivir que hacerlo en Dios: «Hallo, en fin, que ser muerto en la memoria / del mundo es lo mejor que en él se asconde / pues es la paga dél muerte y olvido, / y en un rincón vivir con la vitoria / de sí, puesto el querer tan sólo adonde / es premio el mismo Dios de lo servido" (vv. 9-14).

El deseo de allegarse a la fuente de que se partió debe ser el afán del hombre, mientras disfruta de esta vida terrena, "del alma temporal destierro» (v. 114), como la llamaría en la "Carta al señor Don Bernardino de Mendoza», pues no

56. García (2010: 799).

57. Lejarza y Uribe (1957: 171).

58. Andrés (1976: 92-93). 
es verdadera vida la de «quien al supremo Autor de vida / no aspira con vital y ardiente celo» (vv. 3-4), «do no sube el mortal, caduco velo» (v. 8), según afirma en el poema XLvir. Un deseo fervoroso que refrenda también, con la misma fuerza que en la "Carta a Arias Montano", en el poema LviI, en el que el cielo aparece como espacio de paz y quietud divinas, frente a la enojosa vida: ${ }_{i} \mathrm{Oh}$, si tras tanto mal, grave y contino, / roto su velo mísero y doliente / el alma, con un vuelo diligente, / volviese a la región de donde vino!» (vv. 5-8).

Al fin y al cabo, tanto la paulina y franciscana búsqueda amorosa de Dios, como esa vuelta al origen de donde partió el alma, eran procesos naturales en la mística afectivista y en la poesía animista de la contemplación, pues, como afirma en la epístola a Montano de nuevo, "¿qué debiera ser, bien contemplando, el alma sino un eco resonante / a la eterna beldad que está llamando?» (vv. 58-60). Pero no se olvide una vez más que se trataba de la concepción que había elaborado ya en su poema al «Parto de la Virgen»:59 "Aquí pues alma mía debes llegada / sin contrapeso desta musa grave, / cual eco responder de Dios llamada / a tan piadosa voz clara y süave» (vv. 745-748). En los versos de la epístola, por cierto, no ha habido apenas investigador que no señale el trasfondo del mito clásico de Narciso y Eco, citados por Aldana, e incluso quien advierte su error al servirse de un personaje que no podía amar sino a sí mismo. ${ }^{60} \mathrm{El}$ símil, sin embargo, podría interpretarse de otro modo. Al cabo, el alma, afirmaba el poeta, no era sino la resonancia de la eterna beldad, esto es, la misma música divina en un movimiento circular de vuelta, de tal modo que el alma no era sino parte de Dios que retornaba a él, de donde había salido, o Dios mismo. Nuestro sobrecelestial Narciso, por tanto, se estaba mirando y amando a sí mismo cuando miraba al alma, como en un espejo-eco.

Por último, llamada el alma e iluminada por la gracia y luz divinas, comienza su vuelo hacia la contemplación y posterior unión con Dios. Aquí, la epístola de Aldana exhibe quizá, de acuerdo con el Tercer Abecedario del franciscano Francisco de Osuna, una integración de alma y cuerpo ${ }^{61}$, como en un intento de superar el neoplatonismo, pues no se atiene solo en ese vuelo a los sentidos espirituales, como la vista, más propio de la "contemplación», sino a los sentidos más propiamente materiales: «Ojos, oídos, pies, manos, y boca, / hablando, obrando, andando, oyendo y viendo / serán del mar de Dios cubierta roca» (vv. 82-84). Una vez negados los sentidos corporales, inmersos en el gozo divino y vueltos hacia la contemplación, al alma le será «quietud el movimiento / cual círculo mental sobre el divino / centro, glorioso origen del contento» (vv. 88-90), esto es, Aldana recurre a la teoría difundida por la geometría mística y el hermetismo, que se sirve del símbolo de la circun-

59. Como había señalado, entre otros, Lefebvre (1953: 187) y Lara Garrido (1985: 440).

60. Sebold (2006).

61. Como había señalado Andrés Martín (1988: 472), Osuna propone como punto de partida de todo trabajo espiritual la integración de alma y cuerpo en unidad de naturaleza, negando todo platonismo, y a su zaga otros muchos como Lope de Salazar y Salinas y místicos posteriores. 
ferencia, donde punto y línea se igualan. A ello volverá luego: «veráse como línea producida / del punto eterno» (vv. 151-152). Una teoría, en definitiva, que tampoco era novedosa en la poesía de Aldana. No en vano, había aludido ya a ella en varias ocasiones, como en las octavas del «Parto de la Virgen»: «mírase el centro que es su propia esfera, / Dios único, infalible y trascendiente» (vv. 757-758), y «pues cuanto el sin rodeo centro dispensa / tanto dispensa el centro sin esfera, / estando cada cual del otro adentro / más que en el mismo punto el mismo centro; / digo que la sin punto principiante / línea infinita que en sí misma vuelve» (vv. 925-930).

Los ejemplos y analogías entre la carta y el resto de su poesía religiosa podrían multiplicarse, como ha señalado la tradición de estudios aldanescos. Basten, no obstante, los ofrecidos como muestra del sentido pleno que rezuman sus versos, al margen de los que conforman su epístola a Montano, y como evidencia de su temprana e inmutable inquietud espiritual, agravada, como en cualquier otro, con los años.

Por lo que respecta a su pensamiento religioso, ya se ha comentado que el divino Capitán conecta sobre todo con la doctrina de los frailes franciscanos, quienes se consideraban caminantes hacia la trascendencia, viadores hacia Dios, ${ }^{62}$ - su carta no muestra otra cosa, de hecho- y que esa espiritualidad se encuentra en Aldana desde muy joven. Por añadir algún ejemplo más, no sería nada extraño que, tras estos versos en los que alude a la necesidad de parar y callar en la escalada hacia la contemplación divina, «Déjese descansar de cuando en cuando / sin procurar subir» (vv. 175-176) y «sin dar ni recibir propia sentencia / que en tal lugar la lengua más despierta / es de natura error y balbucencia» (vv. 184-186), se encontrase el siguiente consejo de san Pedro de Alcántara:

La contemplación es haber ya sacado esta centella; quiero decir, haberla hallado ese afecto y sentimiento que se buscaba y estar con reposo y silencio gozando de él, no con muchos discursos y especulaciones del entendimiento, sino con una simple vista de la verdad [...], como tomado el puerto cesa la navegación [...], y así como el hombre se sintiere inflamar del amor de Dios, debe luego dejar todos estos discursos y pensamientos, por muy altos que parezcan, no porque sean malos, sino porque entonces son impeditivos de otro bien mayor. ${ }^{63}$

Del mismo modo, es posible que la alusión a los bienes sobreesenciales de Dios que recoge la carta, «ilustradas advertencias / de las musas de Dios sobreesenciales» (v. 266), se debiese a otro ilustre franciscano y comentarista de Areopagita, como san Buenaventura, según nos recuerda el escritor realista Juan Valera:

62. Andrés Martín (1988: 466).

63. Alcántara (1999: 138-139). Años después, san Juan recogería esta misma idea en su Subida al Monte Carmelo: «Aprenda el espiritual a estarse con advertencia amorosa en Dios, con sosiego de entendimiento [...], y muy presto, se infundirá en su alma el divino sosiego y paz con admirables y subidas noticias de Dios, envueltas en divino amor. Y no se entremeta en formas, meditaciones e imaginaciones, o algún discurso, porque no desasosiegue al alma y la saque de su contento y paz, en lo cual ella recibe desabrimiento y repugnancia» (Cruz 1995: 198). 
Toda la ciencia y todo el arte de la mística se resumen y contienen, como dice el doctor seráfico San Buenaventura, en estos tres puntos: ¿Quién soy yo? ¿Quién es Dios? ¿Cómo Dios y yo seremos una misma cosa? Implica lo primero el conocimiento de sí mismo; lo segundo, un estudio teológico del Ser Supremo, a quien no conocemos bien por la razón y debemos verle en la oscuridad de la fe, y lo tercero se logra sólo después de la contemplación sobreesencial, alzándose el alma, abstraída de toda imagen y de toda idea que no sea de Dios mismo, por cima de su propia esencia creada, y subiendo hasta el ser increado del alma, que es su centro. El centro del alma Dios es, dice el santo. ${ }^{64}$

Es Dionisio Areopagita, en cualquier caso, quien difundió la idea de lo «sobreesencial», que fray Juan de los Ángeles utilizaría luego, aunque este lo hiciera a través de Francisco de Aldana, cuyos versos, no en vano, llega a citar en sus Consideraciones sobre el Cantar de los cantares de 1607. También el Areopagita, como el neoplatonismo, desarrolla la teoría circular del movimiento divino, del alma que vuelve a su origen. Pero con él, también numerosos franciscanos, entre los que podría señalarse como otra fuente posible de Aldana a Juan de Cazalla, quien defiende, al igual que el poeta, la idea de que el hombre que ama a Dios es «medianero» entre Dios y las criaturas: «Considera agora, yo te ruego, cómo todas las cosas proceden del amor de Dios y cómo por el amor que el hombre tiene a Dios se vuelven todas en ese mesmo Dios. ¡Oh dulce y maravilloso círculo del cual se muestra que el hombre que ama a Dios es un medianero entre Dios y las criaturas, pues por él, amando a Dios, ellas vuelven a su criador! ${ }^{65}$

En otra obra, atribuida al franciscano fray Ambrosio de Montesino, por ejemplo, se alude a la universal creación divina, entre la que incluye, como muestra de su amor, al ser más insignificante: «qualquier cristiano deve firmemente creer que Dios es universal criador de todas las cosas visibles e invisibles, y que no hay gusanillo alguno ni florezilla que no sea criada por Dios» ${ }^{66}$. Se trata esta de una alusión al gusanillo que recuerda muy cerca los siguientes versos de la carta de Aldana: «Enamórase el alma en ver cuán bueno / es Dios, que un gusanillo le podría / llamar su crïador de lleno en lleno» (vv. 169-171).

Es, con todo, Francisco de Osuna quien parece ofrecer más pasajes a la obra poética de Aldana y, en particular, a su "Carta a Arias Montano». Afortunadamente, la crítica aldanesca ha estado tan atenta en su detección, como prolija en su anotación. ${ }^{67}$ Pero no me resisto por ello a señalar algún pasaje más de su obra, donde alude a la representación circular de la morada divina tan grata a Aldana: «Has de imaginar una gran circunferencia que no tenga riberas y poner en medio

64. Valera (1881).

65. Cazalla (1974: 111).

66. Sermones de epistolas y evangelios (1995: 221).

67. Baste el ejemplo de Lara Garrido (1985), en cuya edición se anotan numerosas coincidencias entre Aldana y Osuna, tanto de contenido como de expresión. 
un punto, que aquel punto es el tiempo del mundo y la circunferencia redonda es la eternidad celestial en que mora Dios, la cual, como nunca tuvo principio, carece de fin». ${ }^{68}$ Esta figuración, al igual que la que aparece representada mediante el punto y la línea de la circunferencia, como se recordará, se remontaba a Dionisio Areopagita ${ }^{69} \mathrm{Y}$ es que los místicos franciscanos, con Osuna y Laredo a la cabeza, bebieron profusamente, como se sabe, de sus obras, en particular de su difundida Teología mistica. ${ }^{70}$ De ahí que el influjo de las teorías del Areopagita, que bien pudo llegar a Aldana a través de aquellos franciscanos, salga a relucir con frecuencia en su obra poética. No obstante, tanto esta cuestión como algunas que se han señalado se trataron de lugares comunes de amplio recorrido, que difundieron por ello no solo franciscanos españoles, sino también autores más alejados geográficamente, desde Giordano Bruno a Marsilio Ficino, como se ha apuntado ya, y místicos pertenecientes a otras órdenes religiosas, desde agustinos a carmelitas, como señaló con acierto Manuel Morales. ${ }^{71}$

Todo ello viene a insistir, y esto sí que resulta indudable, en la profunda inquietud espiritual del poeta, así como en lo innecesario de explicar sus últimos versos por una suerte de conversión religiosa. Francisco de Aldana, por supuesto, no era seguramente un experto teólogo, como algunos llegaron con razón a afirmar, pero su conocimiento de las obras espirituales más relevantes de su tiempo parece demostrado. Y no solo las de aquellos místicos franciscanos del recogimiento, con cuya doctrina, en mi opinión, su familia estaba especialmente vinculada. Algunos fragmentos de su "Carta a Arias Montano» coinciden de tal modo con las ideas que presentan las obras de otros religiosos que me resisto a creer que no hubiese llegado a leerlas. Pese a que no son pocos, como digo, los que podrían señalarse, valgan, para finalizar, los dos casos que siguen.

El primero es el del Libro de la oración que fray Luis de Granada compuso en 1554. Allí no solo alude, por ejemplo, al mismo "divino piélago» en el que se hunde el alma que describe Aldana, sino que, entre otras coincidencias, alude al vacío sin pie o abismo de la nada en la que se encontraba el alma antes de ser:

Estando tú en esas tinieblas y en ese abismo tan profundo de la nada, plugo a aquella infinita bondad y misericordia, por pura gracia, usar contigo de su virtud y omnipotencia y sacarte con su poderosa mano de aquellas tinieblas y de aquel abismo tan profundo del no ser al ser, y hacer que fueses algo. ${ }^{72}$

68. Osuna (2002: 388-389).

69. La teoría circular, que describía a Dios como «esfera infinita, cuyo centro está en todos sitios y la circunferencia en ninguno», que se remonta al Corpus Herméticum y a autores como Hermes Trismegisto, fue compartida por numerosos autores posteriores. La recoge Cipriano de la Huerga citando a los cabalistas, Montano y Giordano Bruno, e incluso antes de ellos Marsilio Ficino y Pico della Mirandola. Véase Fernández López (2013: 49; 52-53).

70. González Pérez (1986).

71. Morales (2003).

72. Granada (1994: 225). 
El segundo, bastante curioso en mi opinión, es el de fray Héctor Pinto, el famoso enemigo de fray Luis de León, y su traducción de la Imagen de la vida cristiana, que publicó en 1571. En esta obra se mencionan cuestiones como «las alas de amor» con las que asciende el alma, el amor de la "causa primera en que se inflama el alma en la divina contemplación», la «escala de Jacob» por la que suben a Dios las almas, abrasadas por ardientes llamas de amor divino, o como, una vez más, la geometría circular de Dios, asuntos todos mencionados en los poemas de Aldana:

Toda la bondad está en el punto medio de la esfera del cual procede la hermosura de ella mesma. La esfera tiene un punto en el medio que se llama centro, del cual salen las líneas a la circunferencia. [...]. Así como el centro es uno, indivisible y está en el medio y de él salen las líneas a la circunferencia, así Dios es una unidad simplicísima, un acto purísimo, que está en todas las cosas, del cual proceden los rayos de la hermosura de las criaturas. Él está dentro en nosotros y es fuente de todo el ser, ser de nuestro mesmo ser, más íntimo a nosotros que nosotros mesmos. ${ }^{73}$

Es cierto que, como han señalado algunos, esta misma teoría se describía en La conversión de la Magdalena de Malón de Chaide o en el Triunfo del amor de Dios del franciscano fray Juan de los Ángeles. Pero no hay que olvidar que estas obras se publicaron entre 1588 y 1590 , una vez fallecido, por tanto, nuestro poeta. En cualquier caso, no es mi intención demostrar, pues sería seguramente una tarea estéril, pese a las muchas coincidencias, que Aldana llegara a leer aquella traducción, sino más bien, como he intentado desde un principio, señalar el enorme y concreto trasfondo espiritual de su poesía. Una poesía unitaria y con pleno sentido desde su juventud.

73. Pinto (1967: 205-206). 


\section{Bibliografía}

Abad Pérez, A., y Sánchez Fuertes, C., «La descalcez franciscana en España, Hispanoamérica y Extremo Oriente», Archivo Ibero-Americano, 59 (1999), 457-788.

Alcalá, Ángel, «Epílogo» a Ben Rekers, Arias Montano, Madrid, Taurus, 1973.

—, "Arias Montano y el familismo flamenco: una nueva revisión», Anatomía del Humanismo. Benito Arias Montano 1598-1998, Luis Gómez Canseco, Huelva, Universidad de Hueva, 1998, 85-109.

Alcántara, Pedro de, Tratado de la oración y meditación, Eduardo Bustamante, Madrid, Rialp, 1999.

Aldana, Francisco de, Poesías castellanas completas, José Lara Garrido, Madrid, Cátedra, 1985.

Amez Prieto, H., "Los descalzos de san Francisco en Extremadura, desde fray Juan de Guadalupe hasta fray Pedro de Alcántara», San Pedro de Alcántara, hombre universal. Congreso de Guadalupe, 1997, Sebastián García, Cáceres, Ediciones Guadalupe, 1998, 113-222.

Andrés Martín, Melquíades, La teología española en el siglo XVI: I, Madrid, BAC, 1976.

-, «La espiritualidad franciscana en España en tiempo de las observancias», Studia Histórica, 6 (1998), 465-479.

Arias de Quintana Dueñas, Jacinto, Antigüedades y santos de Alcántara, Madrid, Mateo Fernández, 1661.

Arias Montano, Benito, Comentario a los treinta y un primeros salmos de David, M. Asunción Sánchez Manzano, León, Universidad de León, 1999, 2 vols.

Bernáldez Bernáldez, Manuel Pedro, "Desde las aguas del olvido: un rastro de la familia Aldana en Alcántara», Alcántara, 67 (2007), 9-24.

Carrasco Martínez, A., «Los Mendoza y lo sagrado. Piedad y símbolo religioso en la cultura nobiliaria», Cuadernos de Historia Moderna, 25 (2000), 233-269.

Cazalla, Juan de, Lumbre del alma, J. Martínez de Bujanda, Madrid, FUE, 1974.

Cernuda, Luis, «Tres poetas metafísicos», Bulletin of Spanish Studies, 25 (1948), 109-188.

Cruz, Juan de la, Subida al monte Carmelo, José Vicente Rodríguez, Madrid, Editorial Espiritualidad, 1995.

Fernández López, Sergio, «Exégesis, erudición y fuentes en el Apparatus de la Biblia Regia", Antigüedades Hebraicas. Tratados exegéticos de la Biblia Regia. Antiquitatum Iudicarum Libri IX. Aparatus sacer, Sergio Fernández López y Luis Gómez Canseco, Huelva, Universidad de Huelva, 2013, 43-85.

García, Miguel Ángel, «Sin que la muerte al estorbo sea». Nueva lectura crítica de Francisco de Aldana, Mérida, Editora Regional de Extremadura, 2010.

Gómez Canseco, Luis, Poesía y contemplación. Las Divinas Nupcias de Benito Arias Montano y su entorno literario, Huelva, Universidad de Huelva, 2007. 
González Pérez, M. Angélica, «La Teología Mística de Dionisio Areopagita y su influjo en místicos españoles del siglo XVI», Teología y Vida, 17 (1986), 291-311.

González Talavera, Blanca M., Presencia y mecenazgo español en la Florencia medicea: de Cosme I a Fernando I, Granada, Universidad de Granada, Tesis Doctoral, 2011.

Granada, Luis de, Libro de la oración y meditación, Álvaro Huerga, Madrid, FUE, 1994.

Green, Otis H., España y la tradición occidental. El espiritu castellano en la literatura desde "El Cid» hasta Caderón, Madrid, Gredos, 1969, 4 vols.

Herranz Migueláñez, Julio, "Espiritualidad de la descalcez alcantarina», San Pedro de Alcántara, hombre universal. Congreso de Guadalupe, 1997, Sebastián García, Cáceres, Ediciones Guadalupe, 1998, 307-340.

Lara Garrido, José, «Introducción» a Poesías castellanas completas, José Lara Garrido, Madrid, Cátedra, 1985, 13-119.

—, "Tratar esto es solo a ti debido»: las huellas del Dictatum Christianum en la Epistola a Arias Montano de Francisco de Aldana», Silva. Studia Philologica in honorem Isaias Lerner, Isabel Lozano-Renieblas y Juan Carlos Mercado, Madrid, Castalia, 2001, 371-391.

Lefebvre, Alfredo, La poesia del capitán Aldana (1537-1578), Concepción, Universidad de Concepción, 1953.

Lejarza, Miguel de, "Orígenes de la descalcez franciscana», Archivo Ibero-Americano, 22 (1962), 15-131.

Lejarza, Miguel de y Uribe, Ángel, «El retorno al ideal primitivo», Archivo Ibero-Americano, 17 (1957), 17-64.

Menéndez Pelayo, Marcelino, «El capitán Francisco de Aldana», Biblioteca de traductores españoles, Enrique Sánchez Reyes, Santander, Aldus, 1952, vol. I, 52-60.

—, «La poesía mística en España», Estudios y discursos de crítica histórica y literaria II, Santander, Aldus, 1941, 69-110.

Meseguer, Juan, «Programa de gobierno del P. Francisco de Quiñones, ministro general O. F. M. (1523-1528)», Archivo Ibero-Americano, 21 (1961), 5-51.

Morales Borrero, M., La geometría mistica del alma en la literatura española del siglo de oro. Notas y puntualizaciones, Madrid, Universidad Pontificia de Salamanca/ FUE, 1975.

Morocho Gayo, Gaspar, «Trayectoria humanística de Benito Arias Montano II. Años de plenitud (158-1598)", III Jornadas sobre humanismo extremeño, Trujillo, Real Academia de Extremadura, 1999, 227-304.

Navarro Durán, Rosa, «Introducción» a Francisco de Aldana, Poesía, Rosa Navarro Durán, Barcelona, Planeta, 1994, IX-LIII.

Osuna, Francisco de, Tercer abecedario espiritual, Melquíades Andrés Martín, Madrid, BAC, 1972.

—, Quinto abecedario espiritual, Mariano Quirós García, Madrid, FUE, 2002. 
—, Primer abecedario espiritual, J. Juan Morcillo Pérez, Madrid, Cisneros, 2004. Pablo Maroto, Daniel de, Reformas y espirituales franciscanos en el Renacimiento, Salamanca, Universidad Pontificia de Salamanca, 2003.

Pozuelo Calero, Bartolomé, «De la sátira epistolar y la carta en verso a la epístola moral vernácula», La epistola. V Encuentro Internacional sobre la poesía del Siglo de Oro, Begoña López Bueno, Sevilla, Universidad de Sevilla, 2000, 61-99.

Prieto García, Antonio, "Francisco de Aldana», La poesía española del siglo XVI. Andáis tras mis escritos, Madrid, Cátedra, 1984, 262-283.

Rivers, Elías L., Francisco de Aldana. El divino capitán, Badajoz, Diputación Provincial, 1955.

—, «Introducción» a Francisco de Aldana, Poesías, Elías L. Rivers, Madrid, Espasa Calpe, 1957, XI-LV.

Rodríguez, Juan Carlos, Teoría e historia de la producción ideológica. Las primeras literaturas burguesas (siglo XVI), Madrid, Akal, 1990.

Rodríguez Moñino, Antonio, El capitán Francisco de Aldana, poeta del siglo XVI (1537-1578), Valladolid, Colegio Universitario de Santa Cruz, 1943.

—, «Noticia preliminar» a Francisco de Aldana, Epistolario poético completo, Antonio Rodríguez Moñino, Madrid, Turner, 1978, 5-27.

Ruiz Silva, Carlos, Estudios sobre Francisco de Aldana, Valladolid, Universidad de Valladolid, 1981.

Ruiz, Raúl, «Introducción» a Francisco de Aldana, Sonetos, Raúl Ruiz, Madrid, Hiperión, 1984, 9-41.

Sebold, Russell P., «Francisco de Aldana: su lucha existencial ante la risa del llanto", Salina, 20 (2006), 81-90.

Sermones de Epistolas y Evangelios por todo el año de fray Ambrosio de Montesino, María Matesanz del Barrio, Madrid, Universidad Complutense, 1995.

Spalding, Jack, Santi di Tito, Nueva York, Garland publishing, 1982.

Traducción de la imagen de vida cristiana de fray Héctor Pinto, Edward Glaser, Barcelona, Juan Flors, 1967.

Uribe, Ángel, «Espiritualidad de la descalcez franciscana», Archivo Ibero-Americano, 22 (1962), 133-161.

Valencia, Pedro de, La lección cristiana de Arias Montano. Obras completas IX/2. Escritos espirituales, Antonio María Martín Rodríguez y José Luis Paradinas, León, Universidad de León, 2002.

VAlera, Juan, "Del misticismo de la poesía española», Discursos académicos, $<$ http://www.cervantesvirtual.com/obra-visor/discursos-academicos--0/ html/ff395d86-82b1-11df-acc7-002185ce6064_5.html>.

Vossler, Karl, «Francisco de Aldana», Escritores y poetas de España, Madrid, Espasa Calpe, 1944, 109-114. 
